\title{
Monitor Device
}

National Cancer Institute

\section{Source}

National Cancer Institute. Monitor Device. NCI Thesaurus. Code C50074.

A device than includes a sensor designed to give information about the presence of a substance or the state of a system. 